\title{
CONSENSUS BULDING THROUGH SYSTEMS THINKING THE CASE OF POLICY AND PLANNING IN HEALTHCARE
}

\author{
Kambiz E. Maani \\ School of Business and Economics \\ The University of Auckland \\ Email:k.maani@auckland.ac.nz
}

\begin{abstract}
This paper discusses a methodology and a case study using qualitative system dynamics to create consensus, team leaming and shared vision in a public organisation. The case involves determining planning priorities for a Division of the Ministry of Health in New Zealand, leading to the creation of a business plan.

The methodology involves Systems Thinking using Group Model Building (GMB) - A three-step process starting with structured brainstorming using the partial KJ (Jiro Kawakita) technique to identify priority areas and then clustering them into 'affinity' groups. Next, the priority clusters are used by the paricipants to construct causal loop diagrams representing 'systems of priorities' (in contrast with list of priorities). Finally, through a group process, leverage points or key priorities are identified as the basis for a business plan. While the above process was well agreed upon by the participants at the outset, strong group resistance was encountered when managers attempted to reduce the number of priority areas. Systems thinking approach was used to create consensus and the commitment to the outcome.

The GMB approach offers significant promise in using qualitative system dynamics with non-systems experts. The methodology can be applied to change management initiative and complex decisions such as restructuring, reengineering, and supply chain design. The expected outcomes are greater commitment and shared vision.
\end{abstract}

Key Words: Group Model Building, Team Learning, Consensus Building, Qualitative System Dynamics, Change Management, and Planning

\section{NTRODUCTION}

The case study reported here is based on a Ministry of Health $(\mathrm{MoH})$ project involving operational and business planning for one of its Divisions. The Division employs staff with diverse professional and policy backgrounds and varying periods of tenure with the Division.

The main question of the planning exercise was the selection of key priority areas (6-7) to focus the limited resources and efforts of the Division. While the project brief required the use of systems thinking approach, it also specified that this had to be conducted in an indirect and implicit manner. Given the short time periods allotted for planning workshops and the lack of familiarity of the participants with systems thinking modelling, this posed a significant facilitation challenge. Therefore, in consultation with Division manager, a series of workshops were designed to accommodate Division's requirements. This paper describes the policy and priority setting process for this Division and highlights the use of Systems Thinking modelling to transform contentious issues into mutual agreement and commitment. Before the process is described, a brief review of relevant literature follows.

\section{LITERATURE REVIEW}

Lack of commitment to decisions is often a key factor in resistance to policy change and organisational initiatives. As the experience has shown, Change Management projects are fraught with stories of resistance to change, sapping morale and adverse consequences in organisations. The likelihood and magnitude of the adverse consequence are greatest where divergent groups, ie, different Divisions, department or units are involved.

'Messy' problems are defined as situations in which there are large differences of opinion about the problem or even on the question of whether there is a problem (Ackoff, 1974; 1979). Messy situations make it difficult for a management team to reach agreement. System Dynamics (SD) modelling with groups known as Group Model Building (GMB) is a powerful tool for dealing with these. SD and GMB are especially effective in dealing with semi-structured and ill-structured decision situations.

GMB offers an opportunity to align and share piecemeal mental models (Huz et al. 1997) and create the possibility of assimilating and integrating partial mental models into a holistic system description (Vennix 1995; 1996). GMB and SD can help uncover 'illusions' that may occur due to the fact that the definition of a problem may be a socially constructed phenomenon that has not been put to test.

Vennix (1999) identifies two sources of messy problems, namely, the individual, and the group/team that give rise to the existence of messy situations. Limited information processing capacity (Vennix 1990), and perceptions and reality constructions (Schutz 1962) are the main contributors to the individual sources of messy problems. Increasing the information processing capacity not only affects the dynamics of a system but also it's causal feedback structure (Dorner 1980). One of the implications of this individual source on GMB is that both qualitative and quantitative modelling are important (Coyle 1999; Vennix et al. 1993). 
The group sources of messy problems relate to deficiencies in group interaction, and the self-fulfilling nature of reality construction in groups. People not only construct reality in their minds, but their behaviour also causes their mental model to become reality in their environment. Deficiencies in group interaction are in the form of mixing up of cognitive tasks (Rogers \& Roethlisberger 1988), lack of critical investigation (Janis \& Mann 1977), and the way team members communicate (Argyris, 1990).

The above points highlight the need for a group facilitator in the GMB process. A facilitator is a person who acts as a 'role model' for the group, a person who can avoid the common deficiencies in group interaction, which negatively affect the quality of the decision (Vennix et al. 1993). Systems thinking interventions will be much more effective if SD and MB tools are skilfully combined with adequate facilitation (Senge, 1990).

Critical characteristics of an effective facilitator include a primary concern with procedure and process and only indirectly with the content, i.e. with the how rather than what. Both attitudes and skills are important characteristics of the 'ideal' facilitator (Vennix 1996,1999). Some of the facilitation attitudes are a helping and inquiring attitude (asks questions rather than provide answers), which, at the same time is neutral with regard to the content of discussion. A facilitator should be able to foster reflection and learning in a team by discouraging defensive communication, while maintaining his/her own integrity and authenticity.

Other important facilitation skills are a thorough knowledge of SD and MB as well as group process techniques. The latter requires an awareness of the existence of various cognitive tasks that a group can encounter. Conflict handling and efficient two-way communication are other important facilitation skills (Vennix 1999).

Group model building need not lead to model quantification and simulation. Vennix (1999) argues that, due to existence of persistent cognitive and social barriers to learning (Argyris 1990; 1994; Senge 1990), simulations are not ultimate solutions. In fact, quantification will either add to understanding the issue or will be dangerously misleading (Wolstenholme 1992; 1999; Coyle 1999). Active construction of the model is just as important as playing it. Thus, it is important to recognise that in a number of cases it is not always useful or even desirable to go through the whole model-building cycle.

In summary, when conducting interventions through GMB, one should be aware that cognitive limitations, differences in perceptions (leading to multiple realities) and ineffective communication patterns (which block productive discussion of these multiple realities) play a key role in the success of the intervention. At the educational level, this requires teaching facilitation skills and group dynamics in SD programmes to engender appropriate attitudes and skills for effective GMB facilitation (Haslett et al. 1999).

The following sections describe a case study using group model building and facilitation in a real life situation.

\section{ISSUES IDENTIFICATION AND METHODOLOGY}

The first step in the Division's priority and planning process was to establish a common ground and create a safe space for group dialogue. This required a shared understanding of what the real and perceived barriers to progress were. The key issues arose out of an initial round of "Checking Ins" whereby the participants shared their thoughts and feelings about various issues. The methodology used in this step was a modified $\mathrm{KJ}$ or Affinity procedure. The methodology is described in Systems Thinking and Modelling (Maani and Cavana, 2000, p.34):

The Affinity Diagrams method, also known as $\mathrm{KJ}$, is a process of mapping creative group thoughts and ideas. The aim of this process is to allow new thought patterns and breakthroughs emerge naturally from a large pool of 'raw' ideas. The Affinity/KJ technique has three main applications:

- Formulation of vague problems

- Synthesis of non-numerical data (also called semantic or language data)

- Teamwork and consensus building.

There are 7 steps in constructing an Affinity Diagram. ${ }^{1}$

Assemble the right team

Phrase issues to be considered

Generate and record ideas (each on a separate card, or Post-it notes)

Randomly lay out completed cards

Sort cards into related groupings

Create header (or label) cards

Construct the Affinity Diagram by placing the headers and sub-headers (on top of the page) with all the cards beneath them. This should form a column for each cluster.

Using the $\mathrm{KJ}$ methodology the following question was posed for brainstorming. 


\section{"What is preventing us from making faster progress?"}

A total of fifty 'raw' statements were generated (five per participant). The participants then clustered these statements into nineteen headings or key issues as shown in Figure 1. This exercise served as a lead or mental preparation for the next step, namely, identification of priority areas. The question of priority setting in organisations is often contentious as it implies trade-offs need to be made, hence creating winners and losers. Often, this results in open challenges and, even worst, silent resentments that lead to loss of commitment by individuals and groups. It is therefore critical that the issue of priority setting is managed in a systemic (holistic) manner.

\section{Priority Selection}

In the next step, a second workshop was devoted to the following question. The question was phrased as follows:

\section{What are the priorities in health policy in terms of where the Division should be placing its greatest} efforts?

Again the group used the $\mathrm{KJ}$ methodology to identify 'raw' priorities by each individual participant and then cluster these in fewer priority areas. The $\mathrm{KJ}$ method is very beneficial in this process. Not only it avoids awkward disagreements and contradictions, the method converges very quickly yielding visible group consensus. Furthermore, the participants often see the process as 'fun', adding another impetus towards teambuilding. Again as the group was diverse in terms of organisational hierarchies and professional backgrounds, it was important that no priorities were missed or reduced early on and prematurely. The $\mathrm{KJ}$ process thus ensured that all contributions were included. This process resulted in 42 'raw' priority statements, which were clustered into 19 priority areas as shown in Figure 2.

As the management had desired to have only 6-7 priority areas, this seemed to be too large for any practical purposes. Therefore, it felt necessary to reduce the initial set of 19 to 6-7 areas. In order to proceed, a set of criteria was developed by the participants for priority selection. The group later refined these criteria. The final criteria list is shown in Table 1 below.

\section{Table 1 - Criteria for priority selection}

\begin{tabular}{|ll|}
\hline 1. & Realistic - can we marshal the resources? \\
2. & $\begin{array}{l}\text { Is it reasonable and compatible with the Government's direction/ political } \\
\text { environment? }\end{array}$ \\
\hline 3. & Impact - direct impact on Maori health \\
\hline 4. & Quick visible results - within a few weeks or months (maximum 6 months) \\
\hline 5. & Alignment - with Division's mission and other stakeholders \\
\hline 6. & Fundamental cause - cause not symptom focus \\
\hline 7. & Existing initiatives - capitalises on existing initiatives \\
\hline 8. & Planning Horizon - short, medium or long \\
\hline
\end{tabular}

In order to minimise subjectivity, it was deemed pertinent to apply the above criteria objectively. It was agreed by the group to use a priority matrix to rank order the priorities. Thus, a scaled ordinal ranking of $1-5$ was adopted where 1 indicated lowest priority and 5 denoted highest priority. It was also decided that, initially, relative weights should not assigned to the criteria. The group then proceeded to rank each of the 19 priority areas against the seven criteria stated above. The outcome of this process, or the priority matrix, is shown in Table 2.

According to the priority matrix, a clear set of rank ordered priories emerged. As all the participants had agreed and freely contributed the process to this point, it was expected that top priority areas would be selected from the priority matrix. Contrary to this expectation, most participants showed strong resistance to this outcome! This was both surprising and enlightening. It is important to bear in mind that in groups where diversity of tasks and purposes are present this resistance exists whether or not it is voiced. In this case no individual participant was prepared to 'let go' of his or her area of work. Of course, at this stage it was possible for the manager to intervene and use her authority to 'force' or coerce the opposing 'camps' into acceptance. But it soon became apparent that any 'reduction' of priority areas would be counterproductive and damaging to the group's integrity and unity. 


\section{From Priority Selection to a System of Priorities}

To break this impasse, it was agreed to adopt all priority areas. However, this was an impracticable solution and contrary to management's initial objective. At this stage, in order to resolve this apparent conflict we offered to use the systems thinking approach. The underlying philosophy of systems thinking is the primacy of the whole and relationships rather than the individual parts. It was explained that this concept was contrary to treating priorities as independent and isolated elements, as they were originally perceived. Rather, the group needed to view them as part of a priority system, where all priority areas were regarded as indispensable elements of the system (i.e., the business plan). In such a system, while all elements are important for the working of the whole, relative importance and 'timing' of the parts are nevertheless recognised and acknowledged. This is done through the identification of 'leverage' points in Systems Thinking. Thus, the group identified areas that were deemed to have a fundamental (or cause) effect on the whole as leverage areas.

In the implementation phase, the Division started with the 'leverage areas' first and as a team, thereby differentiating the priority areas by timing rather than perceived importance. These interventions in turn would introduce a positive chain effect in the system as a whole. This approach necessitated adopting a new mental model, which transformed the question of 'priority selection' from a reductionistic perspective to a systemic mind set. Having accepted this philosophy and approach, the group converted the priority matrix into several plausible causal loop diagrams (CLD) of priorities. The group then chose one of the CLDs as their preferred one. This CLD is shown in Figure 3. It is interesting to note that the selection of the preferred CLD, unlike the previous priority selection case, was rather quick and unanimous. In this CLD (Figure 3), variables identified by ' $L$ ' indicate leverage points in the systems, where earlier attention and focus will be devoted.

\section{CONCLUSION}

Contentious organisational issues, such as priority selection, program, policy and direction changes often create resistance to change and unspoken resentment. The conventional change management techniques are unable to cope with the dynamic complexity and unintended consequences of such actions. This paper illustrates the application of Systems Thinking and Group Model Building in a Division of the Ministry of Health in New Zealand. The driving question of the planning exercise was to determine a reduced set of priorities for the creation of the Division's business plan.

The methodology involved a three-step process: (1) brainstorming to identify key issues and priority areas, (2) developing a priority matrix, and (3) creating causal loop diagrams representing 'systems of priorities' (in contrast with list of priorities). Using the priority CLDs leverage points or key priority areas were identified as input to the business plan.

The paper illustrates how Systems Thinking methodology could create consensus, team learning and shared vision in today's complex organisations. This approach helped transform 'piecemeal mental models' to shared understanding, acceptance, and commitment to resolving issues and the challenges facing the organisation.

Group Model Building offers significant promise in using qualitative system dynamics with novice users. The methodology can be applied to change management initiatives and complex organizational decisions such as restructuring, reengineering, and supply chain design. The expected outcomes are greater commitment, mutual acceptance and shared vision.

\section{REFERENCES}

Ackoff RA. (1974) Redesigning the Future: a Systems Approach to Societal Problems, New York: Wiley. Ackoff RA. (1979) The future f Operational Research is past. Journal of the Operational Research Society Vol 30, No 2, pp 93-104.

Argyris C. (1990) Overcoming Organizational Defenses, Facilitating Organizational Learning, Boston: Allyn and Bacon.

Argyris C. (1994) Good communication that blocks learning: A Theory of Action Perspective, Reading, MA: Addison-Wesley.

Coyle G. (1999) Qualitative modelling in system dynamics or what are the wise limits of quantification?

Keynote address to the conference of the System Dynamics Society, Wellington, New Zealand

Domer D. (1980) On the difficulties people have in dealing with complexity, Simulation and Games Vol 11, No 1, pp 87-106. 
Haslett T, Barton J, Sarah R. (1999) The Use Of Group Modelling Techniques As A Teaching Tool, In Proceedings of the 1999 International conference of the System Dynamics Society, Wellington, New Zealand.

Huz S, Andersen DF, Richardson GP, Boothroyd R. (1997) A Framework For Evaluating Systems Thinking Interventions: An Experimental Approach To Mental Health System Change, System Dynamics Review, Vol 13, No 2, pp 149-169.

Janis IL \& Mann L. (1977) Decision Making: A Psychological Analysis of Conflict, Choice and Commitment, New York: The Free Press.

Maani K \& Cavana R. (2000) Systems Thinking and Modelling - Understanding Change and Complexity, New Zealand: Prentice Hall.

Rogers CR, Roethlisberger FJ. (1988) Barriers And Gateways To Communication, In: John J. Gabarro, People: Managing Your Most Important Asset, Harvard Business Review, Special Edition of articles, pp 19-25.

Schutz A. (1962) Collected Papers I: The Problem of Social Reality. The Hague: Martinus Nijhoff.

Senge P, (1990). The Fifth Discipline: The Art and Practice of the Learning Organization, New York: Doubleday:.

Vennix JAM. (1990) Mental Models And Computer Models: Design And Evaluation Of A Computer-Based Learning Environment For Policy Making, Ph.D. dissertation, University of Nijmegen, Netherlands

Vennix JAM, Scheper W, Willems R. (1993) Group Model Building: What Does The Client Think Of It? In the Role of Strategic Modelling in International Competitiveness, Proceedings of the 1993 International System Dynamics Conference, Sepada E., Machuca J. (eds). Cancun: Mexico; pp 534-543.

Vennix JAM. (1995) Building Consensus In Strategic Decision-Making: System Dynamics As A Support System, Group Decision and Negotiation, Vol 4, No 4, pp 335-355.

Vennix JAM. (1996) Group Model-Building: Facilitating Team Learning using System Dynamics Chapter 5, Chichester: Wiley.

Vennix JAM. (1999) Group Model Building, System Dynamics Review Vol 15, No 4, pp 379-401.

Wolstenholme E.F. (1992) The Definition And Application Of A Stepwise Approach To Model Conceptualisation And Analysis, European Journal of Operational Research, Vol 59, pp 123-136.

Wolstenholme E.F. (1999) Qualitative Vs Quantitative Modelling: The Evolving Balance, Journal of the Operational Research Society, Vol 50, pp 422-428. 
AJIS

Vol. 9, No. 2

May 2002

Figure 1: Issues Clusters
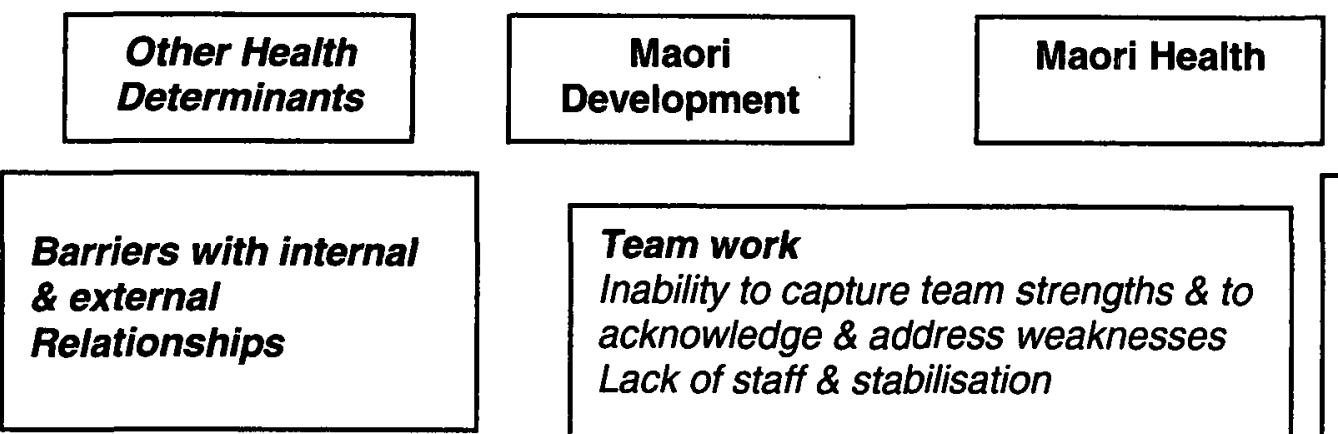

Team work

Inability to capture team strengths \& to acknowledge \& address weaknesses Lack of staff \& stabilisation

\section{Leadership \\ Lack of direction, leadership \& communication \\ Provide the leadership Compass \\ Not leading many of our own projects}

Desire to share power

Reluctance to share power - those in power

Govt. process constraints
Public Health
Ability to influence Lack of resource to support Govt.'s priority for Maori Health Out of decision making loop Get into decision making loop Focus on making a difference Make waves

\section{Turbulent} environment

Turbulence

Change fatigue

Lack of follow through

\section{Maori Health or development}

Maori Health status can't be addressed

by health alone

No consensus re Maori health gain vs

Maori Development

Are we captured by bureaucracy?

Public or Personal Health?

Too focused on personal health

intervention

Personal vs public health?

Being too passive \& not analytical enough

\section{Vision of Maori Health}

Lack of clear definition of

Maori Health Status

MHB - Don't really believe we can do it

Identify a common goal

\section{Time pressure}

Work pressure limits ability for staff development

Lack of time to develop as a team

Too much to deal with

\section{Clear priorities}

Not sure what to do

Lack of focus on priorities

Lack of shared focus

Lack of vision in direction

$A D H O C$ work priorities

Unable to prioritise work (lack of guidance)

MoH-Taking a problem (solving) approach most of the time

Not enough attention \& time given to big issues or questions

Too reactive, not enough proactive
Lack of Effective collaboration with key groups

Relationships with others
Health is part of other things

Responsibility of Health Status is beyond the health sector

Failure to identify (Maori) health statushealth sector responsibility Failure to capture the complexities of the health sector (first up) 
Figure 2 - Priority Areas

Prevention - Public Health

Prevention strategies

Project-Public Health

Approach

Information to better

manage care

(prevention \&

treatment)

Role Models

Whanau Capacity

Health information for

consumers

Incentives for hapu, whanau

Capacity of all providers

Treaty of Waitangi Raise ideas/model for parallel Maori structures

\begin{tabular}{|l|}
\hline $\begin{array}{l}\text { Rural Health } \\
\text { Maori Rural Health } \\
\text { needs }\end{array}$ \\
\begin{tabular}{|l}
\hline $\begin{array}{l}\text { Accountability } \\
\text { Cycle } \\
\text { Accountability } \\
\text { arrangement } \\
\text { documents } \\
\text { Incentives for } \\
\text { funders }\end{array}$ \\
\hline
\end{tabular} \\
\hline
\end{tabular}

\section{Evaluate} monitoring \& evaluation tools

Incentives on providers Integrated care development

\begin{tabular}{|cc|}
\hline Clarify & $\begin{array}{c}\text { Maori Health } \\
\text { model/philoso } \\
\text { phy } \\
\text { Measures }\end{array}$ \\
& Maori Health \\
\hline
\end{tabular}

Disease management Diabetes

\section{Social}

Economical \& Cultural

Economic/Social determinants Highlight how health dependant on education, employment, housing etc Identify structural factors causing increase of Maori in poverty

Increasing the Maori Health Identify funding allocation 
Maori Provider Development advocate funding (at least 5 years) for Maori Health providers

Maori provider workforce development
Maori Workforce Capacity

Maori Workforce

NZMC Rep-MoH

Establish Maori advisors in each

Branch of $\mathrm{MoH}$

\section{High Priority Diseases}

Biggest Killers

Most Common Morbidities

Diabetes

High Priority Health issues affecting Maori
Health Service-Access Barriers, $\$$, cultural, geographical -Research, Service utilisation by income levels
Child \& Youth

Youth Health

Maori Youth, Mental Health,

Suicide profile

Child Health

The Future - Nga Tamariki

Tamariki Ora focus yr 1

Capacity \& Capability of

$\mathrm{MoH}$ to respond

TPK review of $\mathrm{MoH}$
Communication \& Relationship \& Collaboration

Maintaining communication with Providers

Support Maori Providers

Manage relationship with HFA - on

Maori Health

Regular MoH Publications - Health sector developments

Collaborate with HFA, TPK, Treasury, Social Services etc... Stakeholder collaboration (effective) 
Table 2: Priority Matrix

\begin{tabular}{|c|c|c|c|c|c|c|c|c|}
\hline Prlority Area & Realls tic & $\begin{array}{l}\text { Impact on } \\
\text { Maori } \\
\text { Health } \\
\end{array}$ & $\begin{array}{l}\text { Oulck } \\
\text { Vis Ible } \\
\text { Resules }\end{array}$ & Allgnment & $\begin{array}{l}\text { Fundamental } \\
\text { c ause }\end{array}$ & $\begin{array}{l}\text { Capitalise on } \\
\text { other initiatives }\end{array}$ & $\begin{array}{l}\text { Planning } \\
\text { Time }\end{array}$ & Score \\
\hline Accoumballow cycle & 5 & a) & 5 & 5 & 2 & & s & 26 \\
\hline $\begin{array}{l}\text { Developoling Maorl } \\
\text { Models }\end{array}$ & 4 & 3 & 3 & 5 & 5 & & s & 24 \\
\hline $\begin{array}{l}\text { Evaluate monttoring } \\
\text { \& evaluation wools }\end{array}$ & 4 & 4 & 3 & 5 & 2 & & $s$ & 22 \\
\hline Rural Health & 3 & 4 & 2 & 3 & 3 & 4 & 1 & 19 \\
\hline $\begin{array}{l}\text { Maor Provider } \\
\text { Devefopment }\end{array}$ & 5 & 4 & 2 & 5 & 3 & 5 & $\mathrm{~s} . \mathrm{m} . \mathrm{I}$ & 24 \\
\hline $\begin{array}{l}\text { Maori workforce } \\
\text { capacity }\end{array}$ & 4 & 4 & 2 & 5 & 3 & & & 23 \\
\hline $\begin{array}{l}\text { Communtcation. } \\
\text { relatoonship \& } \\
\text { collaboration }\end{array}$ & 5 & 3 & 5 & 5 & 2 & 5 & & 25 \\
\hline $\begin{array}{l}\text { increase Maof } \\
\text { Healun Putea }\end{array}$ & 3 & 3 & 1 & 5 & 4 & 4 & & 20 \\
\hline Disease Mngnt & 2 & 5 & 2 & 5 & 3 & 3 & & 20 \\
\hline $\begin{array}{l}\text { High Prionty } \\
\text { Oiseases }\end{array}$ & 2 & 5 & 2 & 5 & al & 3 & & 21 \\
\hline $\begin{array}{l}\text { Incentve on } \\
\text { Provlders }\end{array}$ & 3 & 2 & 2 & 2 & 3 & 3 & & 15 \\
\hline $\begin{array}{l}\text { Capacto } 8 \\
\text { capabilly of MoH to } \\
\text { Respond }\end{array}$ & 3. & 2 & 3 & 4 & 2 & 3 & & 17 \\
\hline 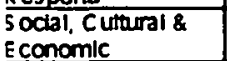 & 3 & 4 & 1 & 5 & 5 & 5 & & 23 \\
\hline Child \& yadr & $\frac{4}{4}$ & 5 & 4 & 5 & 5 & 4 & & 27 \\
\hline Access Bamers & 2 & 5 & 2 & 5 & 4 & 3 & & 21 \\
\hline Whanau Capacto & 3ै & 3 & 2 & 5 & 5 & 3 & & 21 \\
\hline Ireaty of W a ltangl & 3 & 4 & 3 & 5 & 5 & 3 & & 23 \\
\hline $\begin{array}{l}\text { Capacto of all } \\
\text { providers }\end{array}$ & 3 & 3 & 2 & 3 & 3 & 3. & & 17 \\
\hline $\begin{array}{l}\text { Preventon, publlc } \\
\text { nealun }\end{array}$ & 4 & 4 & 3 & 4 & 5 & 4 & & 24 \\
\hline $\begin{array}{l}\text { Scale } \\
1=10 w 5=\text { high } \\
1=\text { no } 5=y \theta s\end{array}$ & $\begin{array}{l}s=\text { short term } \\
m=\text { medium term } \\
l=\text { long term }\end{array}$ & & & & & & & 0 \\
\hline
\end{tabular}


Figure 3 - Priorities CLD

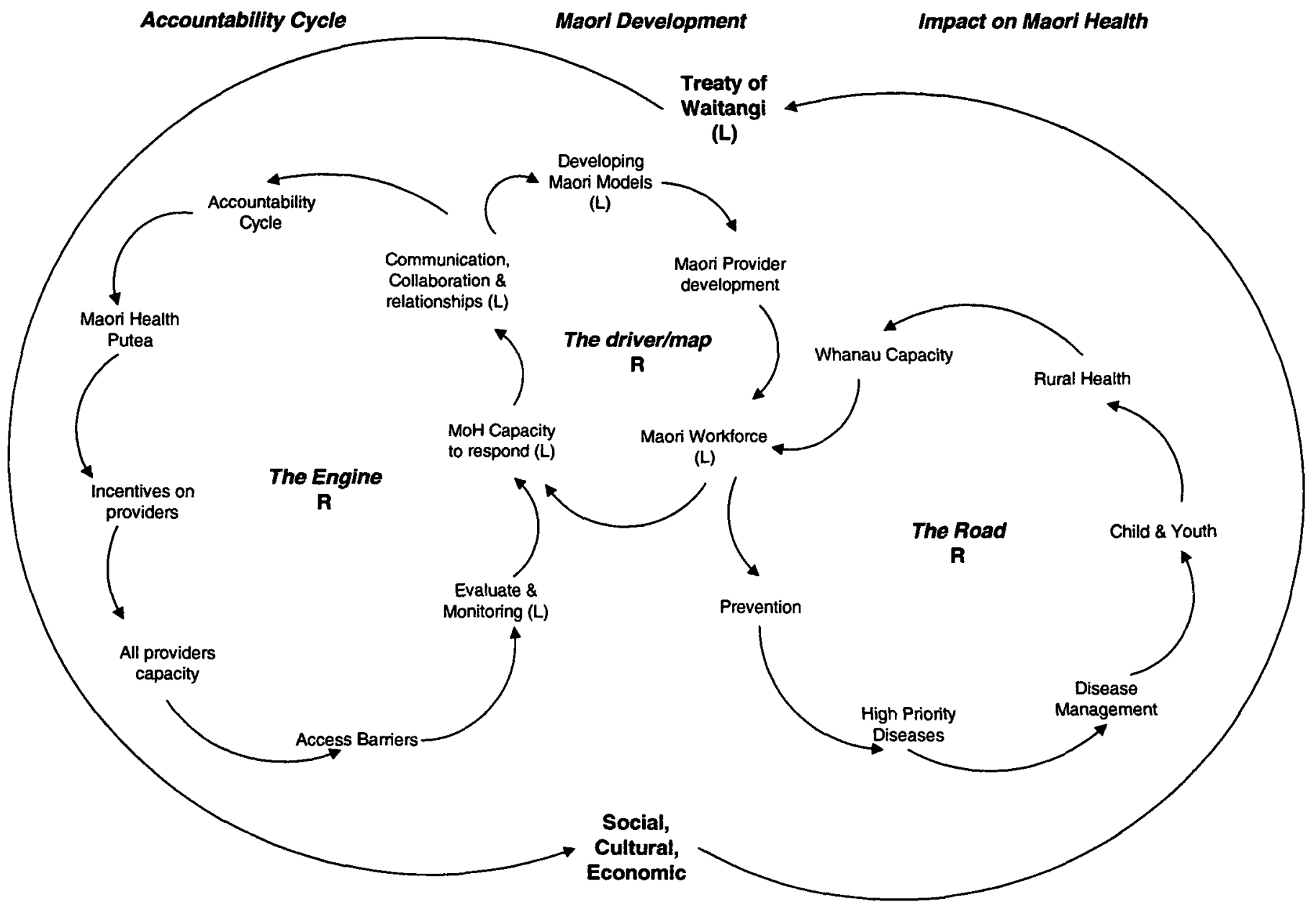

1. Seven Management Tools, Goal/QPC, 1991 